
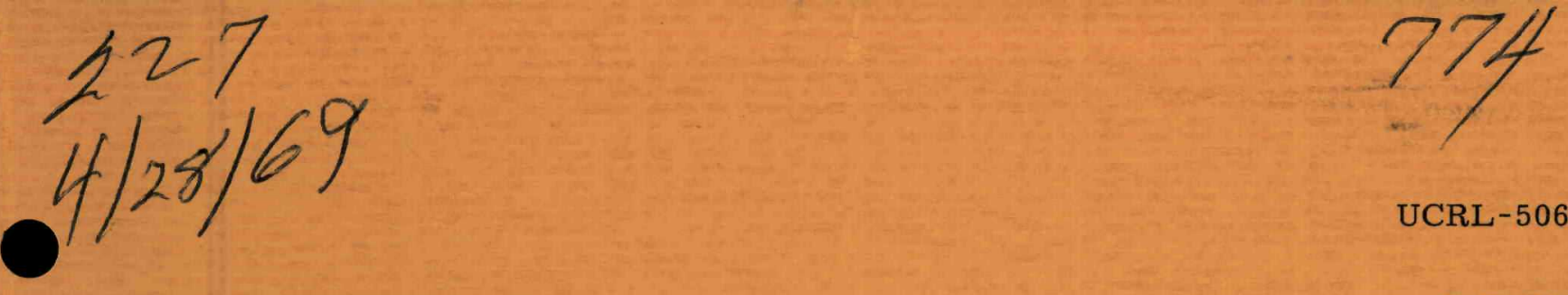

UCRL-50603

\title{
REFRACTORY ALLOY DEVELOPMENT FOR THE ADVANCED SPACE POWER REACTOR PROGRAM
}

L. W. Roberts, Jr.

G. S. Root

March 17, 1969
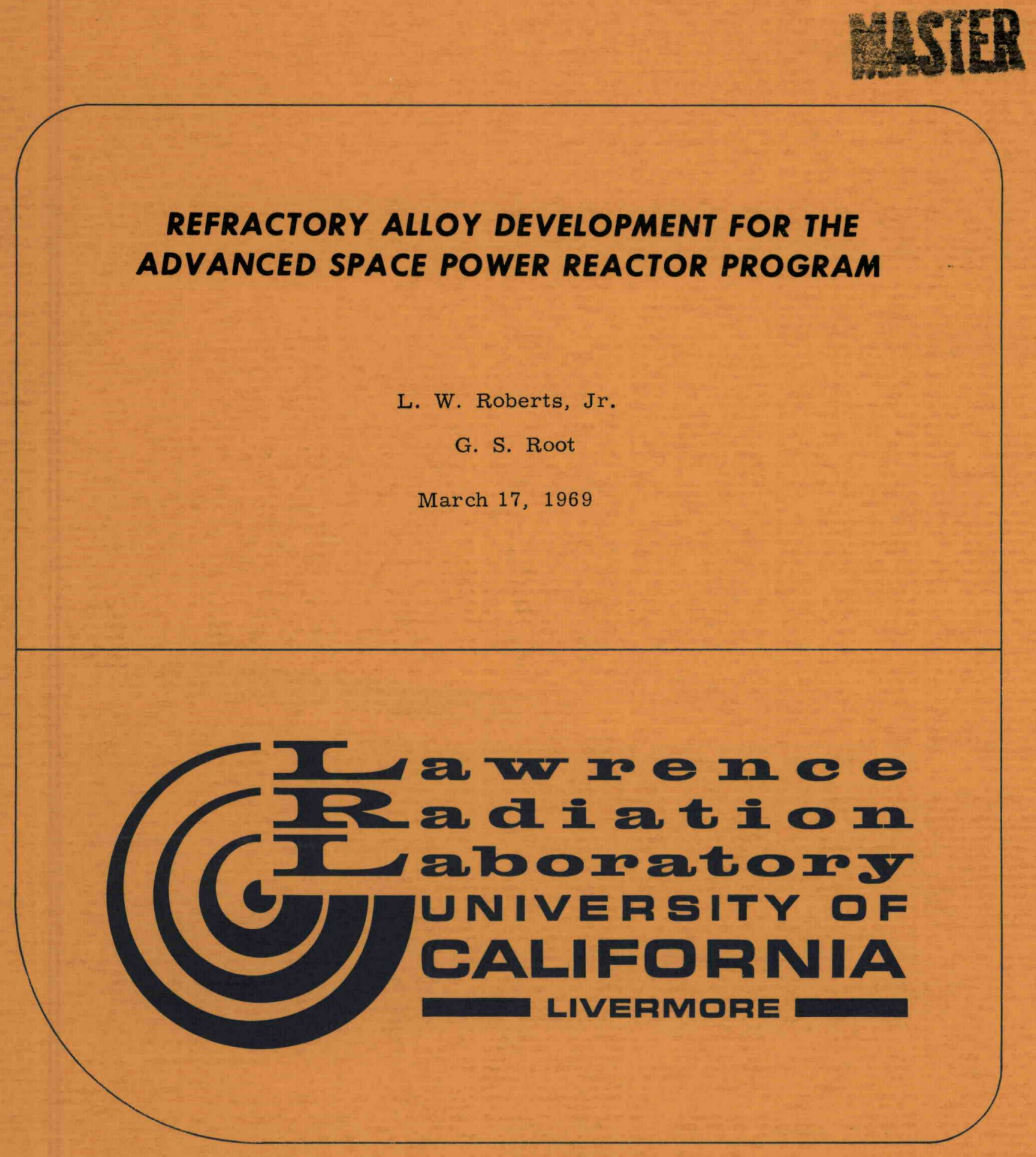


\section{DISCLAIMER}

This report was prepared as an account of work sponsored by an agency of the United States Government. Neither the United States Government nor any agency Thereof, nor any of their employees, makes any warranty, express or implied, or assumes any legal liability or responsibility for the accuracy, completeness, or usefulness of any information, apparatus, product, or process disclosed, or represents that its use would not infringe privately owned rights. Reference herein to any specific commercial product, process, or service by trade name, trademark, manufacturer, or otherwise does not necessarily constitute or imply its endorsement, recommendation, or favoring by the United States Government or any agency thereof. The views and opinions of authors expressed herein do not necessarily state or reflect those of the United States Government or any agency thereof. 


\section{DISCLAIMER}

Portions of this document may be illegible in electronic image products. Images are produced from the best available original document. 
TID-4500, UC-25,

Metals, Ceramics, and Materials

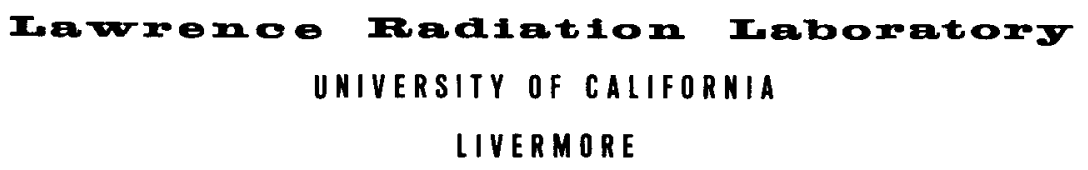

UCRL- 50603

\section{REFRACTORY ALLOY DEVELOPMENT FOR THE ADVANCED SPACE POWER REACTOR PROGRAM}


Blank Page 


\section{Contents}

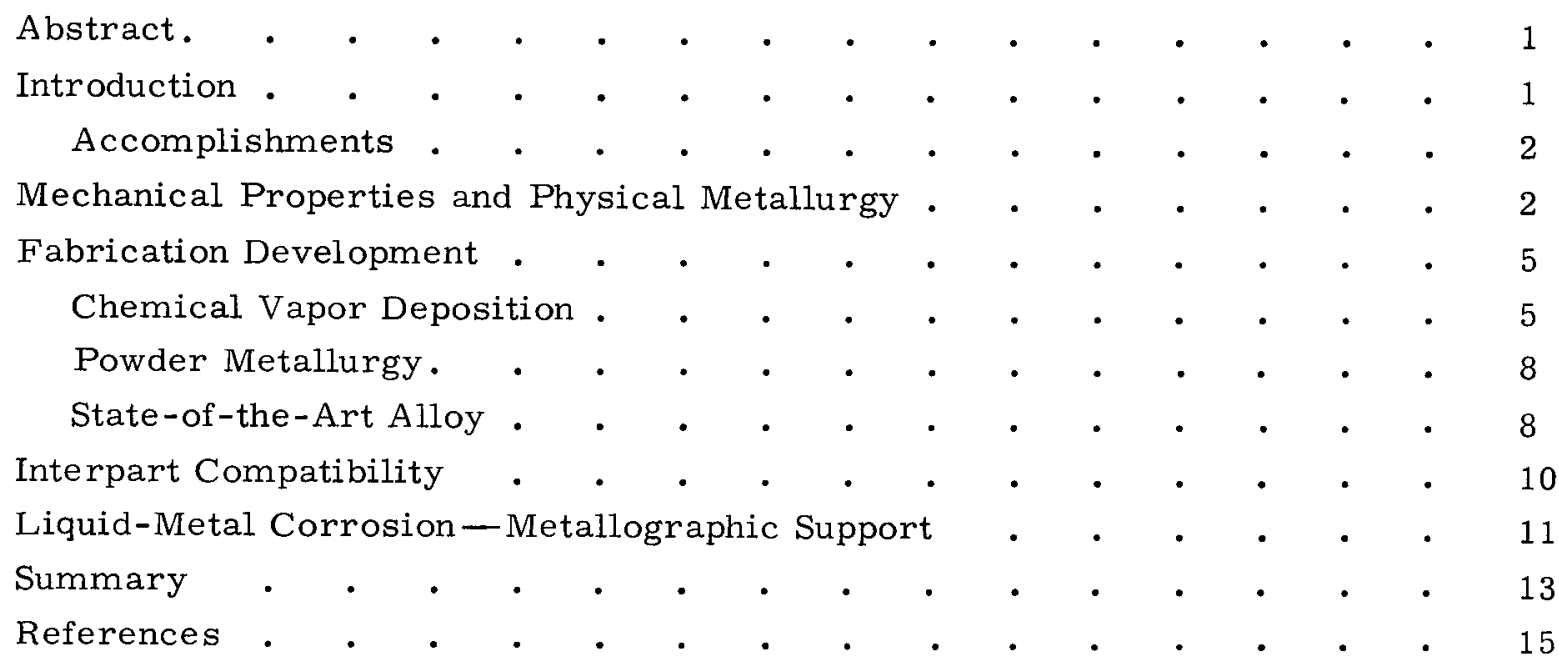

\section{LEGAL NOTICE}

Levernment sponsored work Nelther the United This report was prepared as an account of Government behalf of the Commission

States, nor the Commission, nor any person acting on behall of his A Makes any warranty or representation, expressed or implied, wh respect to the ace racy, completeness, or usefulness of the information contained in this report may not infringe of any information, appara

privately owned rights, or B. Assumes any habilities with respect to the use of, or for dasclosed in this report

se of any information, apparatus, method, or process disthe Commission" includes any emAs used in the above, "person acting on behalf of the Commission" to the extent that ployee or contractor of the Commission, or employee of such of such contractor prepares, such employee or contractor of the Commission, or employent to his employment or contract

disseminates, or provides access to, any information pursuctor. 


\title{
REFRACTORY ALLOY DEVELOPMENT FOR THE ADVANCED SPACE POWER REACTOR PROGRAM
}

\begin{abstract}
This report summarizes the work done by the Metallurgy Division for the Advanced Space Power Reactor Program. We characterized the deformation of $\mathrm{W}$, Re, and $\mathrm{W}-\mathrm{Re}$ alloys at high temperatures and found a basis for developing stronger alloys. A chemical-vapor-deposition process was invented for making $\mathrm{W}-\mathrm{Re}$ tubing with good mechanical properties. Surface contamination of tungsten particles was found to be the obstacle to the incorpora-

tion of submicron second-phase particles in a tungsten matrix. State-of-the-art tungsten-alloy technology was found wanting but amenable to improvement. Welding or bonding T-111 alloy to W-Re-Mo was unsuccessful. Unusual techniques were created to study corrosion of tungsten alloys by lithium. We established a seven-unit facility for tensile creep testing at $10^{-10}$ torr at elevated temperatures.
\end{abstract}

\section{Introduction}

This report is a summary of the work undertaken in the Metallurgy Division for the Advanced Space Power Reactor Program. Included are some evaluations and recommendations not presented elsewhere.

The metallurgical program was concerned with two short-range problems: supporting corrosion studies and evaluating existing mechanical property data. Longer-range objectives - alloy improvement and focusing of fabrication development - were to be based on these preliminary findings. The Advanced Space Power Reactor Program was terminated before the early work could be fully applied to longer-range objectives.

In the selection of reactor structural materials, one must consider mechanical properties, fabricability, and intercomponent (structural) compatibilities, which follow closely in importance the fundamental considerations of fuelstructure and coolant-structure compatibilities. We directed our metallurgical work to these three areas, for which design information was not available.

We began the program having had some experience in chemical vapor deposition, an excellent chemical and metallurgical diagnostic capability, and a well-equipped welding laboratory. However, hightemperature creep equipment consisted of but one ultra-high-vacuum $2400^{\circ} \mathrm{C}$ furnace, and no fabrication equipment was on hand.

For an early entry into the liquid-metal corrosion phase of the evaluation work, we selected the existing technology of General Electric Company's Nuclear Materials and Propulsion Operation (G.E.NMPO) for the manufacture of W-Re-Mo 
ternary alloy tubing for a pumped loop and corrosion capsules. The longer-range objective was to select and evaluate the coolant compatibility of a stronger $\mathrm{W}$-base alloy. At first the choice was not clear, and tubing was unavailable in stronger materials.

The U.S. Bureau of Mines (USBM) and Wah Chang Corporation were chosen to prepare material for mechanical-property screening studies.

\section{ACCOMPLISHMENTS}

We characterized the deformation of $W$, $\mathrm{Re}$, and W-Re alloys between 1400 and $1900^{\circ} \mathrm{C}$, showed the applicability of the data for design purposes, and found a basis for developing stronger alloys.

A chemical-vapor-deposition process was invented and proved for making $\mathrm{W}-\mathrm{Re}$ tubing with room-temperature mechanical properties at least as good as those of wrought products.

Surface contamination of tungsten particles was found to be the obstacle to

\section{Mechanical Properties}

Reactor-loop structural materials and fuel cladding must resist gross plastic deformation by creep at high operating temperatures. Structural elements, in addition, must withstand the acceleration loads of launch and the thermal stresses of startup when their mean temperatures are below or near the ductile-brittle transition temperature of tungsten. It is well known that rhenium imparts roomtemperature toughness to tungsten. In fact, the body-centered-cubic W-25 at. \% Re solid-solution alloy, prepared by the incorporation of high-melting secondphase submicron particles (such as $\mathrm{ThO}_{2}$ ) in a tungsten matrix. A method for producing a dispersion-hardened system was devised but not tested.

State-of-the-art tungsten-alloy technology was evaluated and found wanting but amenable to improvement.

Welding or fusion bonding of $\mathrm{T}-111$ alloy to W-Re-Mo was unsuccessful. By analogy with previous findings with Ta-Mo alloy single crystals, we expect reliable metallurgical joints directly between Group V and Group VI metals to be difficult to attain.

Unusual techniques were created for assembling and metallurgically analyzing lithium tungsten-alloy corrosion experiments.

During this program we established a seven-unit facility for tensile creep testing at $10^{-10}$ torr at temperatures up to $2600^{\circ} \mathrm{C}$.

Elaboration of the above accomplishments, as well as recommendations for future work, are discussed in the following sections.

\section{and Physical Metallurgy}

chemical-vapor deposition at LRL, showed a 75 percent reduction in area in a roomtemperature tensile test. The beneficial effect of $\mathrm{Re}$ on $\mathrm{W}$ at low temperature and the uncertainty of the influence of $R e$ on the strength of $\mathrm{W}$ at high temperature were the motivations for including $\mathrm{W}-\mathrm{Re}$ alloys in our deformation studies,

All our creep tests were performed between 1400 and $1900^{\circ} \mathrm{C}$ at stresses below 10,000 psi. $^{1,2}$ Some of the steady-state tensile creep data for the metals tested are compared with the compressive 
strength of uranium nitride ${ }^{3}$ in Table I. All these metals show promise as cladding materials that could resist diametrical fuel swelling.

Tungsten and all of the alloys had steady-state creep rates $(\dot{\epsilon})$ that could be

Table I. Steady-state creep rates measured at $1600^{\circ} \mathrm{C}$ and 2500 psi.

\begin{tabular}{ll}
\hline $\mathrm{UN}$ & $1 \times 10^{-3} / \mathrm{hr}$ \\
W & $7 \times 10^{-5} / \mathrm{hr}$ \\
$\mathrm{W}-25 \mathrm{Re}$ & $5 \times 10^{-5} / \mathrm{hr}$ \\
$\mathrm{W}-5 \mathrm{Re}$ & $6 \times 10^{-6} / \mathrm{hr}$ \\
$\mathrm{Re}$ & $8 \times 10^{-5} / \mathrm{hr}$ \\
\hline
\end{tabular}

Not including primary strain of 1 to 2 percent, which occurs rapidly after application of load.

characterized by the expression $\dot{\epsilon} \approx\left(\frac{\sigma}{\mathrm{E}}\right)^{\mathrm{n}} \exp \frac{-100}{\mathrm{RT}}$, where $\sigma$ is the applied stress, $\mathrm{E}$ the modulus of elasticity at test temperature, $\mathbf{R}$ the universal gas constant, and $\mathrm{T}$ the absolute temperature. For $\mathrm{W}$ and $\mathrm{W}-5 \mathrm{Re}$, the stress exponent $\mathrm{n}$ was 5.8; for $\mathrm{W}-25 \mathrm{Re}$ and $\mathrm{W}-30 \mathrm{Re}$, $\mathrm{n}$ was 3.8 . However, we observed a change in mechanism when fine-grained W-25 Re was tested at lower strain rates. This change in mechanism illustrates the necessity of performing long-term tests for reactor design data. Extrapolation of the present data to lower strain rates can most conservatively be done by limiting $n$ to 1 at applied stresses less than 2500 psi (Fig. 1). However, it hasn't been demonstrated that these higher stress exponents do not hold at lower stresses in most cases.

Rhenium additions significantly altered the deformation behavior of $\mathrm{W}$ at elevated temperature. At stresses in excess of 2200 psi, large additions strengthened W.

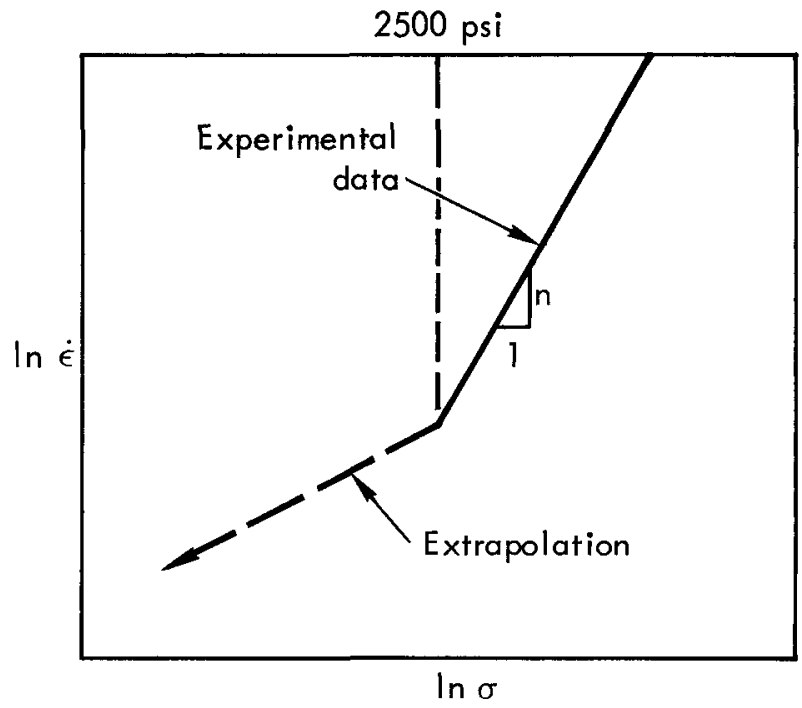

Fig. 1. Strain rate $(\dot{\epsilon})$ vs stress $(\sigma)$ data for tungsten alloys - extrapolated to lower strain rates.

Tungsten-5 Re alloy, however, was stronger than $\mathrm{W}, \mathrm{W}-25 \mathrm{Re}$, or W-30 Re at all stresse less than 10,000 psi between 1400 and $1900^{\circ} \mathrm{C}$. In all concentrations, Re eliminated the 1-2 percent primary creep strain found in W; i.e., steady-state creep rates were immediately established when the load was applied to the alloys.

In general, thermomechanical history and variations in minor-impurity contents did not influence the creep strength of $W$ or W-Re alloys. ${ }^{1}$ However, $\mathrm{W}$ and $\mathrm{W}-\mathrm{Re}$ with grain sizes greater than $50 \mu$ were stronger than finer-grained material at stresses below 3500 psi; i.e., they crept more slowly for a given stress. Also, evidence was obtained that the interplay of second-phase particles and plastic deformation could be a basis for strengthening $\mathrm{W}$ and the $\mathrm{W}-\mathrm{Re}$ alloys.

Tungsten- 30 Re alloys contained a grain-boundary precipitate of the very hard (approximately $1600 \mathrm{DPH}$ ) sigma intermetallic phase. Although the transmission electron microscopy studies revealed dislocation-sigma particle interactions 
within the grain, the interactions were not extensive enough to decrease the creep rate; the mobility of dislocations was not appreciably influenced. Future studies should include attempts to nucleate a finer sigma dispersion within the matrix grains.

Equilibrium dislocation densities were proportional to the 2.3 power of the stress for tungsten and the alloys. Tungsten alone developed subgrains of a size inversely proportional to the applied stress and independent of temperature; the primary creep strain mentioned previously was attributed to the formation of this substructure. Figure 2 shows two creep curves at $1600^{\circ} \mathrm{C}$ for tungsten. For the test at 3500 psi, there was a steady-state rate of about $7 \times 10^{-4} \mathrm{hr}^{-1}$. For the other test, steady state was established at $6000 \mathrm{psi}$ and then the load was reduced to $3500 \mathrm{psi}$, where the creep rate dropped to about $7 \times 10^{-5} \mathrm{hr}^{-1}$ but gradually increased to the value expected at $3500 \mathrm{psi}$. If the finer substructure established at a higher stress could be stabilized at a lower stress by hard dispersed second-phase particles, appreciable strengthening would be obtained.

Rhenium also has a high melting point (Re: $3180^{\circ} \mathrm{C} ; \mathrm{W}: 3410^{\circ} \mathrm{C}$ ) and high elastic modulus (Re: $66.7 \times 10^{6}$ psi; W: $50 \times 10^{6}$ psi). Because it has an hcp structure it was important to compare rhenium with bcc tungsten in creep. Figure 3 summarizes the test results. Between 1500 and $2200^{\circ} \mathrm{C}$, the

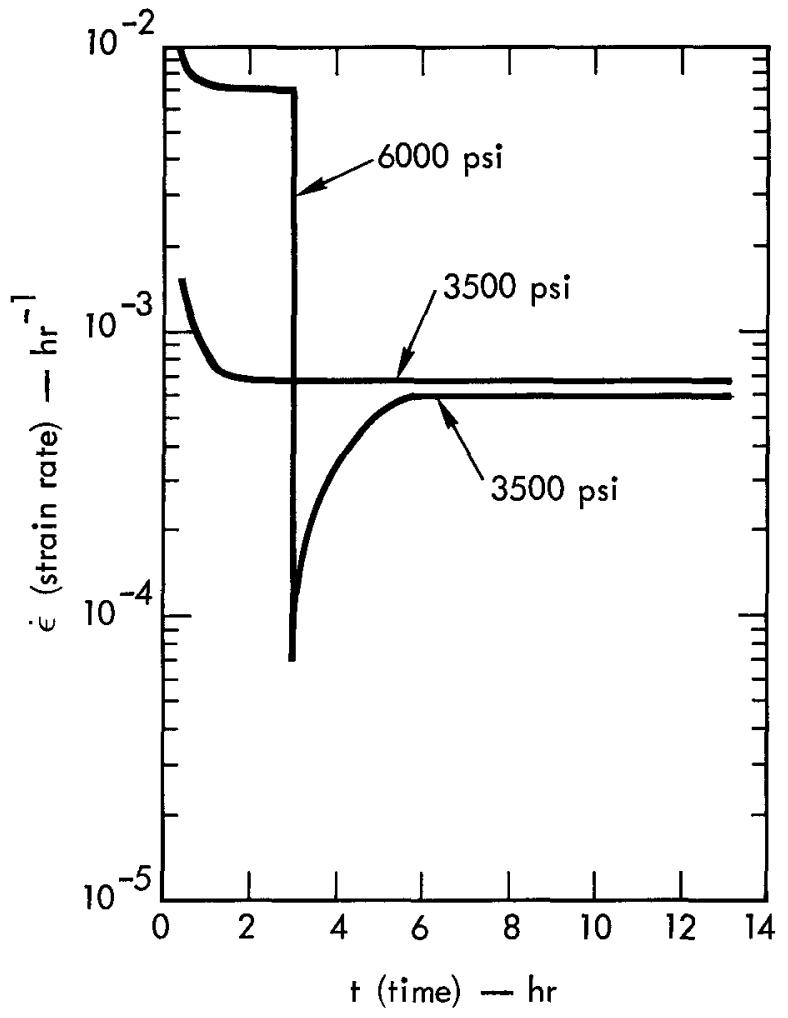

Fig. 2. Creep curves for tungsten at $1600^{\circ} \mathrm{C}$.

steady-state creep rate of Re depended on stress to the 3.4 power. ${ }^{4}$ The apparent activation energy for creep was $60 \mathrm{kcal} /$ mole, in contrast to 100 for tungsten and the alloys. There was no primary creep for the conditions of temperature, stress (1,500-10,000 psi), or grain size studied. Anomalously in Re, dislocation densities in annealed or annealed-and-crept specimens were $10^{9} / \mathrm{cm}^{2}$, invariant of stress or temperature. Since Re has limited slip systems, dispersion hardening could prove exceptionally effective in increasing its creep resistance. 


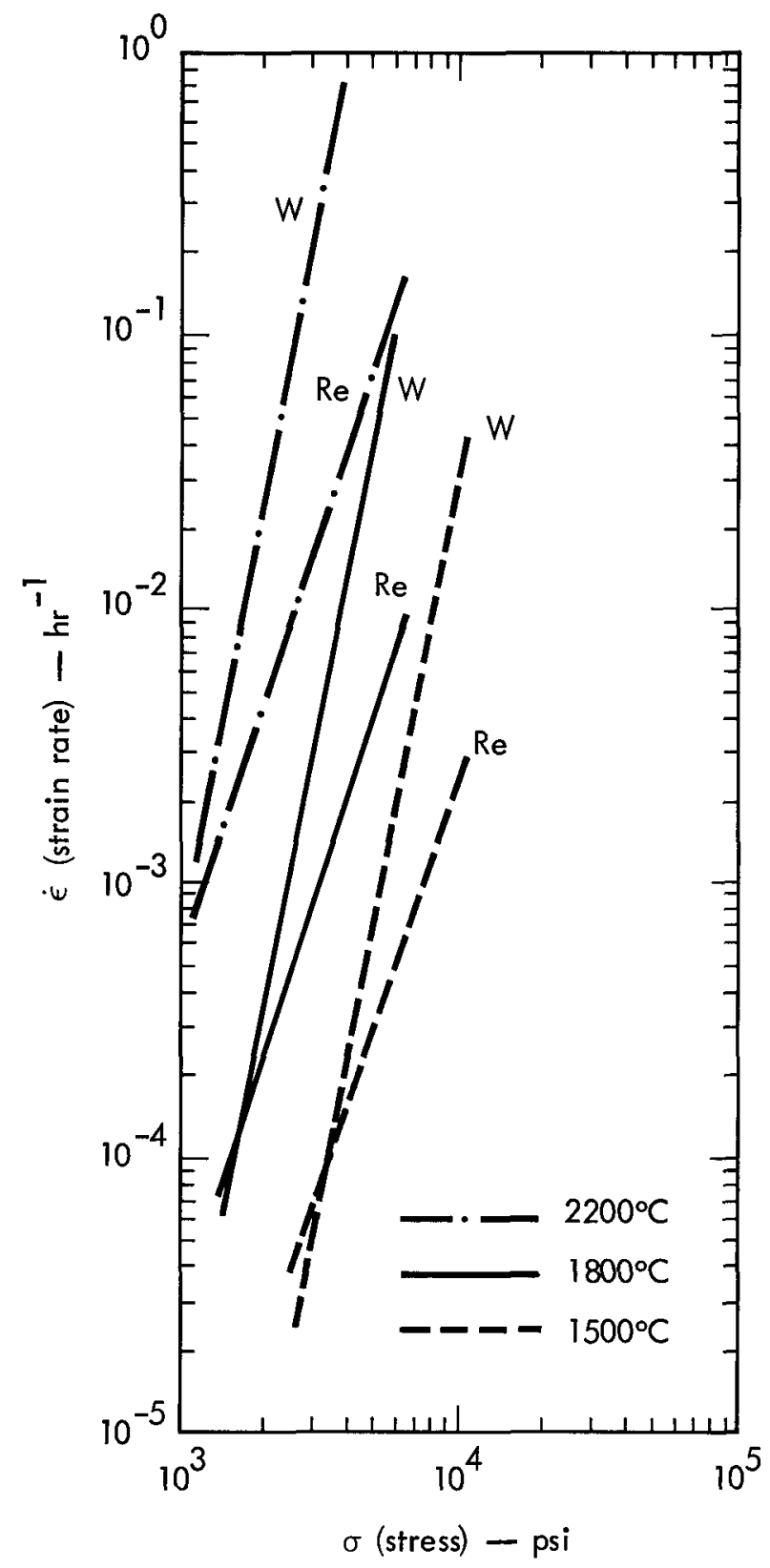

Fig. 3. Comparison of creep data for tungsten and rhenium.

\section{Fabrication Development}

\section{CHEMICAL VAPOR DEPOSITION}

Hydrogen reduction of $\mathrm{WF}_{6}$ and coreduction of $\mathrm{WF}_{6}$ with $\mathrm{ReF}_{6}$ were used to produce mechanically sound tubing for liquidmetal containment; e.g., cladding or heat pipes. Reaction parameter studies were done on short lengths to find ways of making a range of strong alloy compositions at useful rates.

Later, we built an apparatus ${ }^{5}$ to make long tubes (see Fig. 4). We used it to make 1 -ft lengths of W-25 Re tubing $1 / 2$ in. in diameter by $0.040-$ in. wall. Longer 


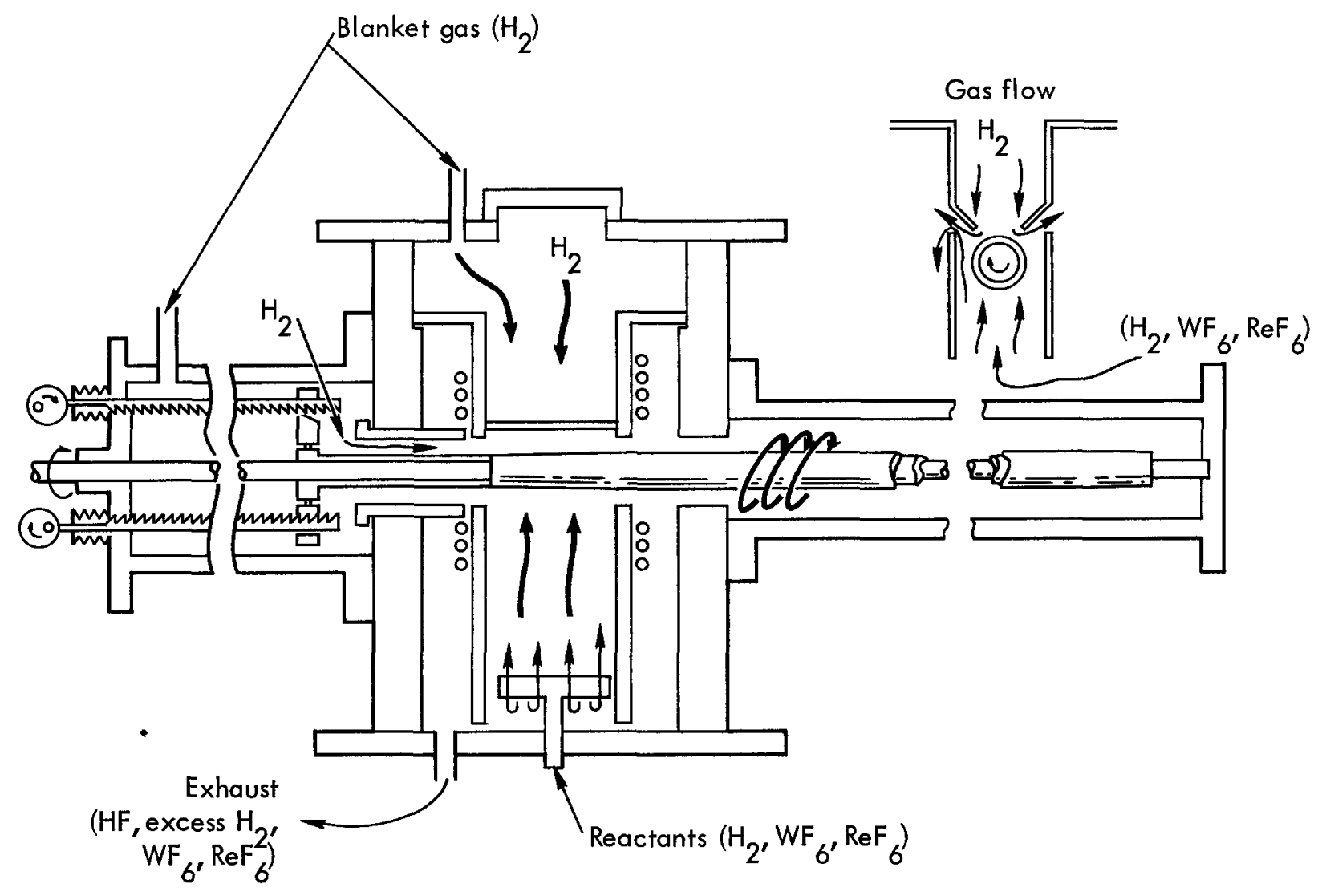

Fig. 4. Chemical-vapor-deposition apparatus for making long tubes.

lengths, other sizes, thicker walls, and other compositions could be produced without significantly changing the basic design.

In operation, premixed metal fluorides are introduced with $\mathrm{H}_{2}$ into the reaction zone, and the gas mixture flows vertically across a 4 -in. length of rotating molybdenum mandrel. Metal deposits on the heated mandrel, which is translated through the heated zone at a rate that depends on the thickness desired and on the required reaction parameters (pressure, temperature, mole ratios, flow rates, etc.). For the W-25 Re alloy, the deposition rate was approximately $0.0003 \mathrm{in} . / \mathrm{min}$. The inside surface of the tubing was a replica of the outside surface of the sacrificial mandrel. Thus, the as-plated tubing required finishing on the outside diameter only. Chemical homogeneity in the $\mathrm{W}-\mathrm{Re}$ deposits was closely controlled with the aid of an induction coil designed to minimize temperature gradients in the reaction zone.

Future work could be directed toward an apparatus for plating large cylindrical shells (say, 18 in. diam $\times 36$ in. long) for reactor pressure vessels. Fine-grained, sound, and homogeneous microstructures have been deposited at a rate of $0.00075 \mathrm{in} . / \mathrm{min}$. Further studies should find conditions that produce good deposits at a rate of $0.001 \mathrm{in} . / \mathrm{min}$.

Sound deposits of alloys containing as much as 30 percent Re were made in short lengths. ${ }^{6}$ Figure 5 summarizes the roomtemperature mechanical properties of these various compositions. Mechanical properties of many of the alloy deposits made 


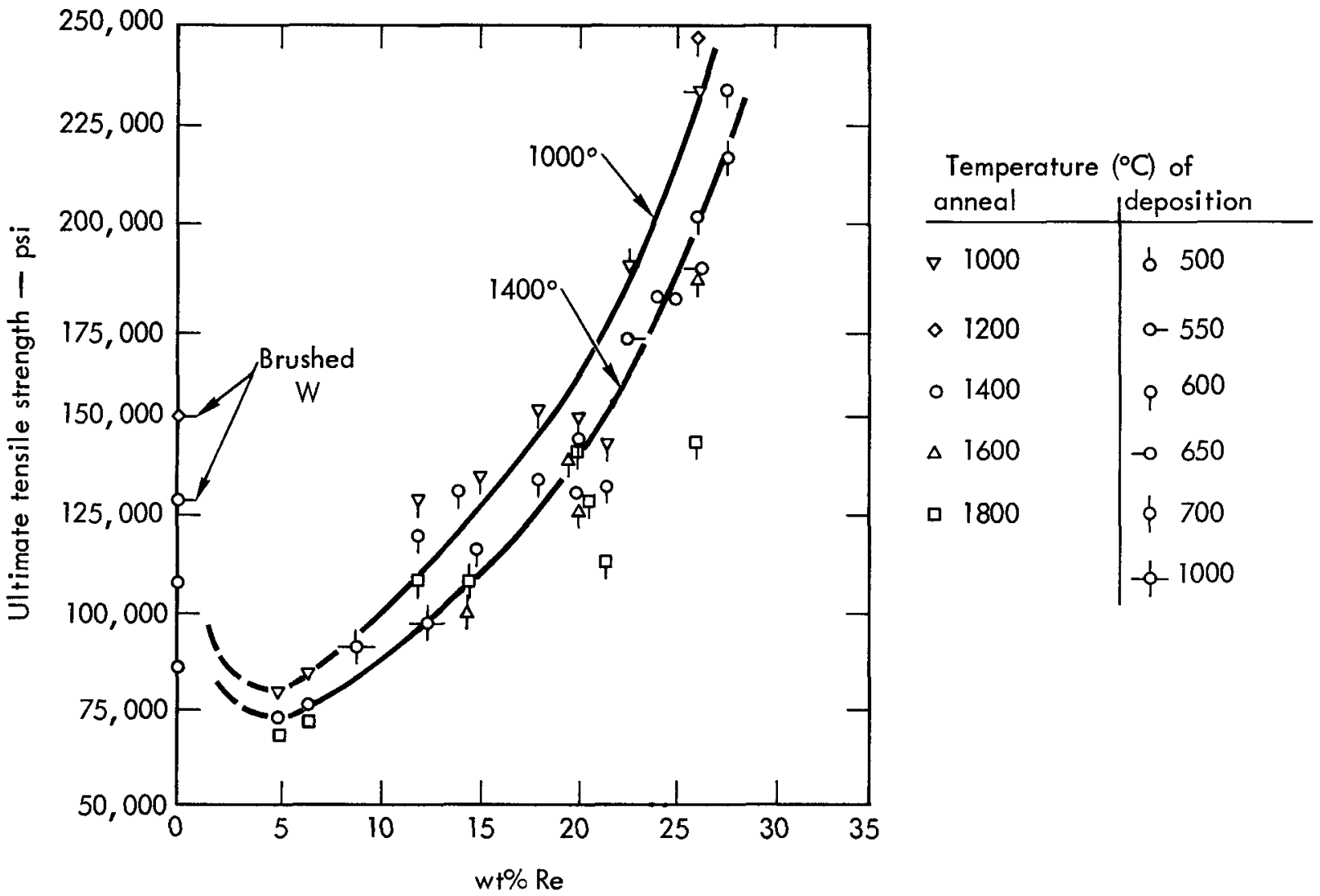

Fig. 5. Tensile strength of CVD W and W-Re alloys.

under optimum conditions ${ }^{7}$ are as good as those found in wrought material originating as an arc melt or as a powder-metallurgy billet. An electron-beam butt fusion weld between two CVD tubes of W-25 Re was free of porosity. Elevated-temperature properties have yet to be compared with those of the materials discussed under mechanical properties and physical metallurgy. Those materials were all rolled from powder-metallurgy billets.

Chemical-vapor deposits typically have coarse, columnar microstructures that are frequently porous and usually mechanically weak. We have used mechanical brushing during plating or deposition of a metastable phase to control the microstructure of all compositions, thereby obtaining good roomtemperature mechanical properties.
Mechanical brushing during deposition of alloys containing up to 18 percent Re produces frequent nucleation of new crystals and results in a controlled fine grain size. ${ }^{7}$

Achieving a fine-grained deposit in alloys containing more than 18 percent Re depends mainly upon another phenomenon. During deposition of the richer compositions, metastable federite (A-15 type phase) forms and coexists with the body-centeredcubic W-Re solid solution. With the proper choice of reaction parameters, the deposit will contain a fine dispersion of this phase. During subsequent annealing, the dispersed metastable phase transforms to the equilibrium structure, and the resulting product is a fine-grained, equiaxed solid solution. 
Deposits with more than 28 percent $R e$ contain a fine dispersion of sigma.

Chemical-vapor deposition may be capable of producing a more optimum distribution of sigma than is obtained by hot working the W-Re powder-metallurgy billet. Thus the process, which offers a way to improve high-temperature properties, should be explored.

\section{POWDER METALLURGY}

A suitable dispersion of insoluble, highmelting particles could stabilize the fine subgrain sizes that develop ${ }^{2}$ when tungsten is crept at high stresses (recall Fig. 2). Interparticle separations should be less than $10 \mu$, and the dispersoids themselves should not represent a large fraction of the composite. A desirable dispersoid would be 2-5 vol \% submicron $\mathrm{ThO}_{2}$ particles.

Historically, attempts to incorporate $\mathrm{ThO}_{2}$ by blending submicron powders and sintering have resulted in coarsening of the $\mathrm{ThO}_{2}$, with the coalescence of the dispersoid occurring at the tungsten grain boundary. In our work we discovered 8 that densification in wet hydrogen, attended by thoria coarsening, proceeded at a much lower temperature (approx $1100^{\circ} \mathrm{C}$ ) than the $2500^{\circ} \mathrm{C}$ temperature normally used for sintering these composites. A tentative explanation for the activated sintering involves the formation of "liquid" interparticle films associated with an interaction between thoria and a tungsten oxide derived from oxygen initially chemisorbed on the particle surfaces. When large volumes (30 percent) $\mathrm{ThO}_{2}$ were sintered with tungsten in moist hydrogen at $1335^{\circ} \mathrm{C}$, all the $\mathrm{ThO}_{2}$ apparently was not consumed by reaction with the tungsten oxide, and the unreacted $\mathrm{ThO}_{2}$ was present within the tungsten grains as particles smaller than $0.1 \mu$.

These observations suggest a powder method for preparing tungsten strengthened with $\mathrm{ThO}_{2}$. The product of a first sintering process could be coarse-ground to liberate the coarse $\mathrm{ThO}_{2}$ from the weakened grain boundaries. After separation of the large $\mathrm{ThO}_{2}$ particles from the $\mathrm{W}$-fine $\mathrm{ThO}_{2}$ composite on the basis of density, the composite powder could be consolidated by hot pressing and/or sintering without further agglomeration, because the $\mathrm{ThO}_{2}$ inclusions would not be available to the new composite-particle surfaces.

Powder densification without additives that may detrimentally influence mechanical properties requires pressure at a moderately high temperature or pressureless sintering at very high temperatures. A consolidation survey ${ }^{9}$ with small-scale apparatus has shown that $98+$ percent densification can be achieved in a few seconds at $1 \mathrm{kbar}$ and $900^{\circ} \mathrm{C}$. Pressures up to $30 \mathrm{kbar}$ and temperatures to $1400^{\circ} \mathrm{C}$ were included in the survey. The Laboratory has a newly installed hot isostatic press that permits the consolidation of a billet up to $8 \mathrm{in}$. diam $\times 16$ in. long with 2 -kbar gas pressure at $1600^{\circ} \mathrm{C}$. We expect that our laboratory findings could be scaled up to produce extrusion billets if necessary.

\section{STATE-OF-THE-ART ALLOY}

G. E. -NMPO technology for making W-25 Re-30 Mo and W-30 Re-30 Mo alloy tubing was the basis of our selection of alloys for initial lithium corrosion experiments. Tooling was designed and built for electron-beam welding G. E.-produced 
components at LRL to make a pumped loop. Machine parameters were established for butt-welding the tubing with our Hamilton Standard electron-beam welder. ${ }^{10}$

Satisfactory full-penetration welds were obtained in the G. E. powder-metallurgy product. However, weld-line porosity after a single-fusion pass was substantially greater than in arc-melt alloy obtained from USBM and G. E. Multiple-pass welding reduced the porosity. We finally settled on a two-pass technique to minimize porosity without severe upsetting (dimensional distortion). From the weldability standpoint, the tubing was satisfactory.

The time-consuming G. E. process for powder and green-compact purification (prior to sintering, hot extrusion, and cold drawing) reportedly eliminated evolution of gases from the finished base metal during welding. It didn't. And, in fact, the need for the expensive process should be reexamined. There are some advantages to the powder-metallurgy process, and therefore this comparison of weldability is not meant to indicate a preference for the arc-melt-origin tubing. Process selection will depend on specific design objectives.

Ternary alloys are at least a factor of 10 weaker in creep near $1400^{\circ} \mathrm{C}$ than the binary alloys. However, they are apparently more amenable to conventional tube-manufacturing techniques. Welded and unwelded tubing of the ternary alloys is now being evaluated by 1500 -psi longitudinal tensile-creep proof tests at $1500^{\circ} \mathrm{C}$. The creep tests will be continued for several thousand hours.

Low-temperature testing of ternary alloys consisted of comparing as-received and fusion butt-welded tubing in tension between room temperature and $400^{\circ} \mathrm{C}$.
Fusion-welded specimens were as strong and tough as coupons machined from asreceived tubing. ${ }^{11}$ Analysis of the test data (Fig. 6) suggests that the G.E.-NMPO drawing process is done too cold $\left(200^{\circ} \mathrm{C}\right)$ and should be performed at $400^{\circ} \mathrm{C}$, where the ductility is higher. In general, the whole cold-working part of the G. E. process could be substantially improved. Strain rates and reductions should be studied in addition to temperature.

The inability of G. E.-NMPO to produce enough sound tubing in time prevented construction of the loop. About 90 percent of the tubing received at the Laboratory was rejected for loop use because it had cracks that extended from the inside surface to as much as half way through the wall. Nondestructive inspection methods were developed at LRL that were sensitive to very shallow flaws as well as to these large ones that had escaped detection at G. E.-NMPO. Standards and techniques were established for in-process inspection at G. E. with the hope of saving time and money in obtaining the balance of the material required for the loop.

Attesting to the low-temperature toughness of these alloys were the deep cracks that had widely opened (large included angle) without propagating through the 0.040-in. wall. The wide openings were indicative of gradual propagation during several of the multiple-drawing operations used to reduce the wall 5 percent per pass. Each of these cold-drawing operations required a new mandrel. It is doubtful that the existing G. E. -NMPO process could be applied to the stronger W-Re binary alloys. As stated before, $W$-Re alloy tubing can be made very easily by the LRL chemical-vapor- 
deposition process. Compositional control of the three-component-alloys would be very difficult, however, by chemicalvapor deposition.

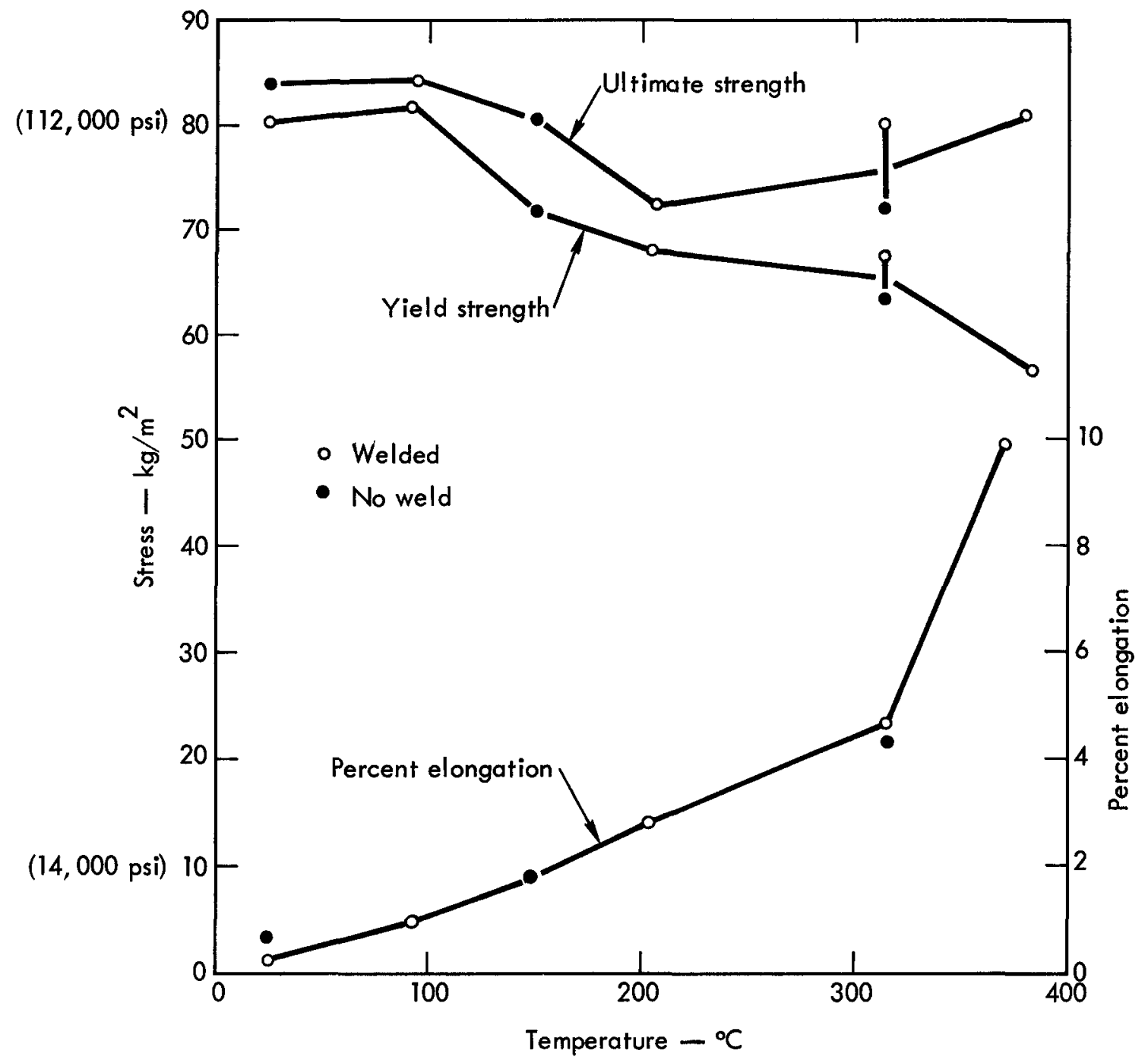

Fig. 6. Temperature dependence of engineering tensile properties of $W-25$ at. $\%$ Re-30 at. \% Mo, 0.5-in.-o. d. × 0.040-in.-wall tubing supplied by G. E.NMPO.

\section{Interpart Compatibility}

The coupling of a tantalum-alloy rankine power-conversion system to a tungstenalloy reactor may require joints between these dissimilar alloys. Fusion welds were tried between W-25 Re-30 Mo and Ta-8 wt \% W-2 wt \% Hf (T-111). ${ }^{11}$ Direct welds were tried, as well as joints with Mo or Mo-50 Re transition consumable inserts in the fusion zone. All joints cracked.

Analyses of the fusion zones and fracture surfaces suggest a fundamental problem. Although no second phases are formed between the Group V ( $\mathrm{Nb}, \mathrm{Ta}$ ) and Group VI (W,Mo) metals, Van Torne and Thomas $^{12}$ report solute clustering on 
the (100) plane in Mo-Ta single crystals and a lowered cleavage stress. Enough corroborating evidence has been collected in our work to say that there is little hope of getting sound, reliable fusion welds directly between components of the two chemical groups. Diffusion bonds between W-25 Re-30 Mo and T-111 were made in $30 \mathrm{~min}$ at $1600^{\circ} \mathrm{C}$ and $10,000 \mathrm{psi}$. They also were fragile and cracked at the interfaces during test-specimen machining. Brazing with a third group metal would depend upon the degree of interdiffusion at reactor operating temperatures. Such joints were not tried.

Interface compatibility was the only compatibility problem considered (other than liquid metal by others) during the program. Potential problem areas in multiple-component systems, in addition to the example above, are the transfer of, say, W onto Ta or Ta onto W through a common liquid-metal stream or the transfer of nitrogen from a dispersion-hardened Group VI alloy to a Group V alloy. One could speculate on a long, long list of difficulties.

Although all the engineering solutions for the construction of a chemically simple power system are not in hand, in our opinion the cost of fabrication development and material characterization for a system composed of many chemical components is unjustifiable, especially when the complications of inter-component compatibility are considered. Further, the performance limitation on either temperature or redundancy cannot be justified.

\section{Liquid-Metal Corrosion-Metallographic Support}

The results and significance of the lithium corrosion work and recommendations for future work are more properly discussed by others. ${ }^{13}$ A brief resume of the metallurgical support to the program is included here to highlight the techniques that were devised at the Laboratory for examination of corrosion samples.

The corrosion damage sustained by a W-25 Re-30 Mo alloy after 1000-hr, hightemperature exposure to flowing lithium was examined metallographically. ${ }^{14} \mathrm{~A}$ test strip was prepared by electropolishing the surface at hot and cold regions prior to exposure. After exposure to liquid metal, polished areas were analyzed by the electron-beam microprobe. Optical micrographs and electron micrographs of replicas were taken from the same areas. Figure 7 summarizes the results. Molybdenum was transported to the colder end of the strip.

Interpretation of the micrographs led to the conclusion about the topology near grain boundaries illustrated by Fig. 8. All of the topography of the sample was developed in the exposure. Microprobe analyses show that the surface roughening was at least in part due to long-range transport, but local redistributions over distances of the order of a grain size may also be responsible for some of the topography. At this point we cannot be certain of the details of the 


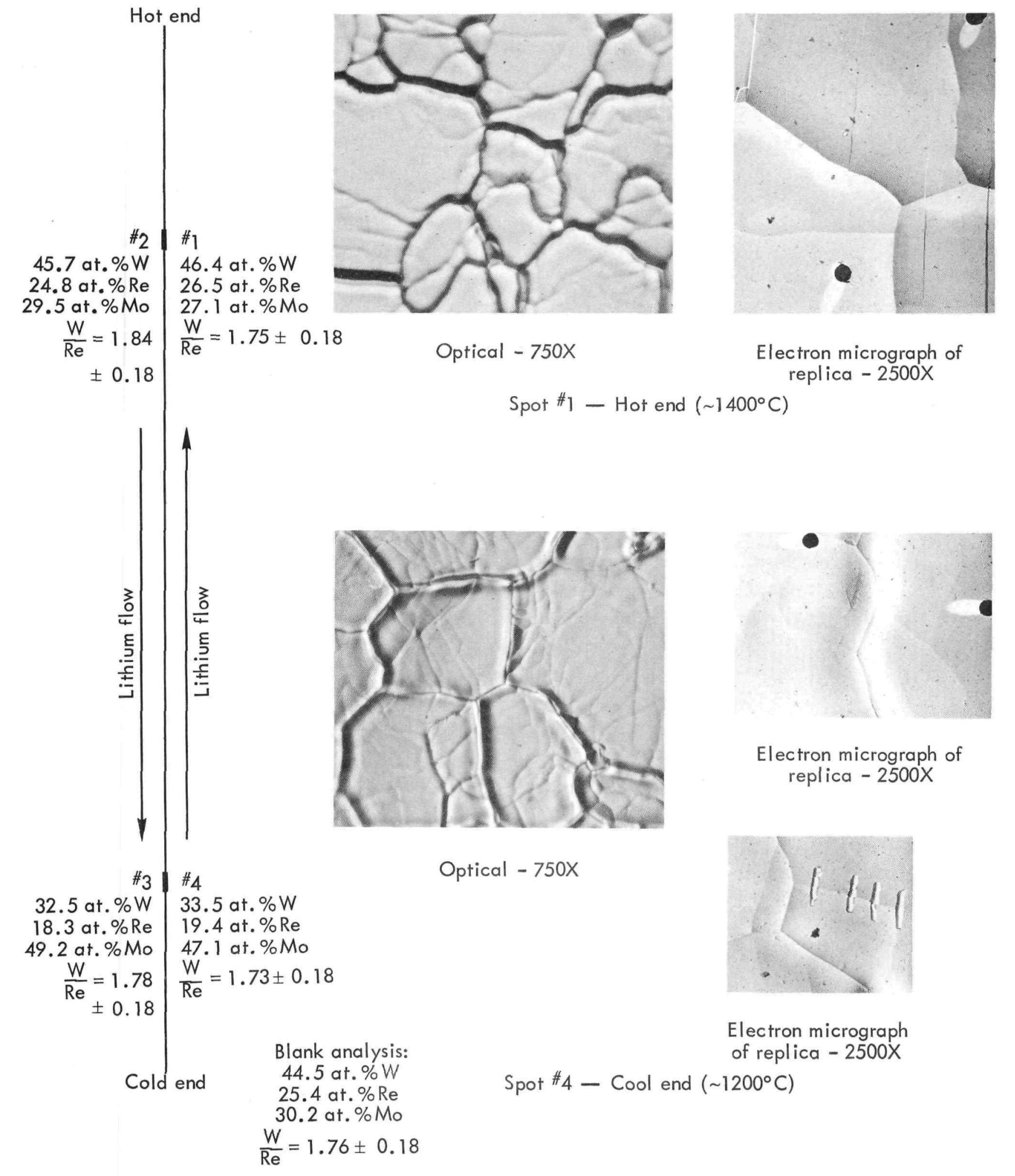

Fig. 7. Microprobe analysis and metallographic examination of W-25 Re-30 Mo alloy after exposure to flowing lithium. The four numbers designate the spots electropolished before exposure. 


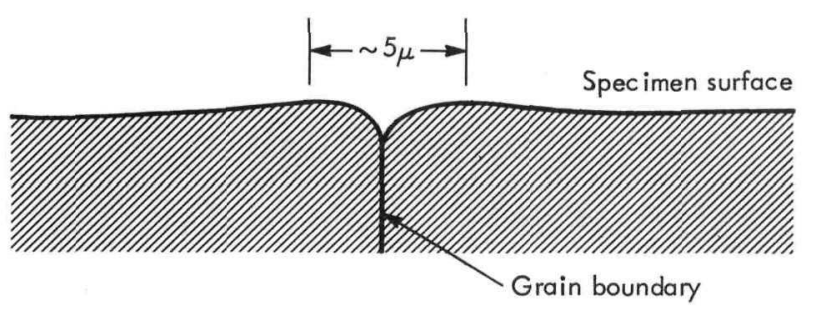

$1400^{\circ} \mathrm{C}$ end

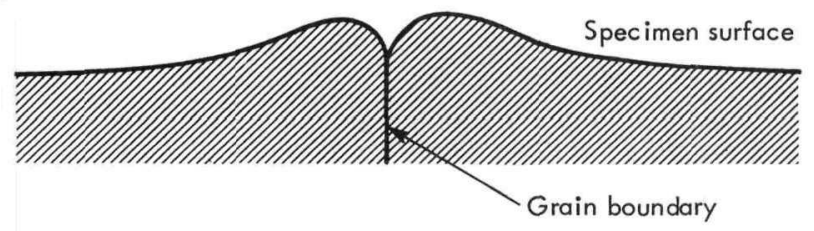

$1200^{\circ} \mathrm{C}$ end

Fig. 8. Schematic diagram of groove shapes developed at the surface of a W-25 Re-30 Mo plate exposed to flowing lithium. removal-precipitation process in this single experiment, but we feel that we have a powerful set of tools for corrosion studies.

More conventional examination of the container itself (micrography of sections through the wall) revealed 0.001-in.-deep intrusions into grain boundaries at the hot end. Such intrusions, depending on their rate of development beyond $1000 \mathrm{hr}$ and their effect on mechanical properties, could severely limit the use of W-Re-Mo alloys for the containment of dynamic liquid lithium above $1400^{\circ} \mathrm{C}$.

No adverse effects of the lithium environment on the low-temperature mechanical properties of the containment alloy were observed after the exposure.

\section{Summary}

We conclude that tubing and even large shells of alloys such as W-5 Re and W-25 Re can be made by chemical-vapor deposition. In addition, chemical-vapor deposition should prove useful for welding dispersion-hardened alloys that are not amenable to fusion welding. The tube manufacturing process itself is a continuous welding process.

All the tungsten-base alloys and the W-5 Re alloy, in particular, are in an underdeveloped state relative to T-111 tantalum-base alloy. Nevertheless, singlephase W-5 Re is as strong as T-111 and can potentially be improved by the same strengthening mechanism that has been used for T-111; namely, the use of secondphase particles to decrease dislocation mobility.
With respect to microstructural features, crept materials fall into three categories:

1) bcc tungsten, which develops subgrains and a stress-dependent dislocation density;

2) bcc tungsten-rich rhenium alloys, which do not develop subgrains but do develop a stress-dependent dislocation density; and

3) hcp rhenium, which develops neither subgrains nor a dislocation density characteristic of the creep conditions.

To complete the survey of the W-Re alloy system and select materials for dispersion hardening, rhenium-rich (hcpmatrix) alloys should be tested. Extensive alloy development, however, should only proceed in concert with liquid-metal, 
metal vapor-liquid, and fuel compatibility work.

We believe an entire reactor-rankine power conversion system could be made from alloys such as Mo-Re, W-Mo-Re, $\mathrm{W}-\mathrm{Re}$, or Re. If it were advantageous for fabricability to use the weaker molybdenum- containing alloys in the colder parts of the system, the G. E. technology could be readily improved. Technological development of the W-Re alloys would be applicable to a system using thermionic conversion from a higher-temperature source than appears useful for rankine conversion. 


\section{References}

1. R. R. Vandervoort and W. L. Barmore, Elevated Temperature Deformation and Electron Microscope Studies of Polycrystalline Tungsten and Tungsten-Rhenium Alloys, Lawrence Radiation Laboratory, Livermore, Rept. UCRL-70524 (1968).

2. R.R. Vandervoort, The Creep Behavior of W-5Re, Lawrence Radiation Laboratory, Livermore, Rept. UCRL-71626 (1969).

3. R. R. Vandervoort, W. L. Barmore, and C. F. Cline, Trans. Met. AIME 242, 1466 (1968). (UCRL-70709 Preprint.)

4. R. R. Vandervoort and W. L. Barmore, High-Temperature Plastic Deformation of Polycrystalline Rhenium, Lawrence Radiation Laboratory, Livermore, Rept. UCRL-71367 (1968).

5. W. R. Holman and F. J. Huegel, An Apparatus for the Production of Tungsten and Tungsten-Rhenium Alloy Tubing by Chemical Vapor Deposition, Lawrence Radiation Laboratory, Livermore, Rept. to be published.

6. W. R. Holman and F. J. Huegel, "CVD Tungsten and Tungsten-Rhenium Alloys for Structural Applications," in Proceedings of the Conference on Chemical Vapor Deposition of Refractory Metals, Alloys, and Compounds, Gatlinburg, Tenn., 1967 (American Nuclear Society, Hinsdale, Ill., 1967), pp. 127-148 (Part I) and 427-442 (Part II).

7. W. R. Holman and F. J. Huegel, Lawrence Radiation Laboratory, Livermore, unpublished data.

8. G. E. Tardiff, On the Sintering Behavior of Submicron Tungsten-Thoria Powder Blends, Lawrence Radiation Laboratory, Livermore, Rept. UCRL-71157 (1968).

9. G. E. Zima and J. F. Lakner, High-Pressure Consolidation of Submicron Tungsten, Lawrence Radiation Laboratory, Livermore, Rept. UCRL-50172 (1966).

10. Quarterly Report, Advanced Space Nuclear Power Program, October-December 1967, Lawrence Radiation Laboratory, Livermore, Rept. UCRL-50004-67-4 Part I (1967).

11. Quarterly Report, Advanced Space Nuclear Power Program, January-March 1968, Lawrence Radiation Laboratory, Livermore, Rept. UCRL-50004-68-1 Part I (1968).

12. L. I. Van Torne and G. Thomas, Acta Met. 14, 621 (1966).

13. R. B. Rozsa, Liquid-Metal Corrosion Experiments - The Pumped Capsule (U), Lawrence Radiation Laboratory, Livermore, Rept. UCRL-50511 (1968) (CRD).

14. G. E. Tardiff, Corrosion Damage to a Tungsten-25 at. \% Rhenium-30 at. \% Molybdenum Containment Alloy after Exposure to Flowing Lithium, Lawrence Radiation Laboratory, Livermore, Rept. UCID-15356 (1968). 


\section{Distribution}

LRL Internal Distribution

Michael M. May

R. Batzel/G. Dorough

J. Hadley

J. S. Kane

B. Rubin

C. Walter

R. Heckman

L. W. Roberts

J. L. Robbins

TID Berkeley

TID File

External Distribution

R. Anderson

U. S. AEC Headquarters

Germantown, Md.

TID-4500 Distribution, UC-25, Metals, Ceramics, and Materials of the Commission

A Makes any warranty or representation expressed or impl ed w th ressect to the accuracy completeness of usefulness of the information con sespect to the accuracy completeness of usefulness of the infornation con
tarned in this seport or that the use of any information apparatus method on tained in this seport or that the use of any information apparatus method
process diselosed in this report maty not infringe privately owned lights or

B Assumes any llabilities with respect to the use of or for damapes resulting from the use of any information apparatus method of process dis closed in this report

As used in the above "person acting on behalf of the Commission" includes any employee or contractor of the Commission or employee of such contractor to the extent that suck employee or contractor of the Cormission or employee of such contractor prepares disseminates or provides access to any nformation pursuant to his employnent or contract with the Commission or his employment with such contractor

Printed in USA. A vailable from the Clearinghouse for Federal Scientific and Technical Information, National Bureau of Standards, U.S. Department of Commerce, Springfield, Virginia 22151 Price: Printed Copy $\$ 3.00$; Microfiche $\$ 0.65$.

$\mathrm{RB} / \mathrm{lm}$ 